\title{
Britain may set up genetics advisory body...
}

London. The British government, in a significant shift from a position adopted only two months ago, has agreed to discuss setting up a transdepartmental advisory committee to monitor both the commercial applications and ethical implications of human genetics.

In doing so, the government appears to have agreed with members of the House of Commons Select Committee on Science and Technology that the existence of such a body might help to reassure the public that the potential dangers of the applications of genetics were being adequately considered.

The new move was announced last week by Stephen Dorrell, the Secretary of State for Health, in reply to questions about the government's response to a report on human genetics published by the select com- mittee last July, after a seven-month inquiry.

Two months ago, in its formal response to the report, the government rejected its main recommendation (see Nature 379, 195; 1996). This was that a Human Genetics Commission be set up, with broad-ranging powers both to monitor and to regulate activities ranging from genetic screening to the way in which genetic information is used by insurance agencies.

At the time, the government claimed that the various aspects of the applications of human genetics were already satisfactorily covered by a range of advisory groups on topics such as gene therapy and genetic engineering experiments, and that a new over-arching commission would merely create additional bureaucracy.

But, in a rare parliamentary move, the all-

\section{... as ethics report clears xenografts}

London. Britain's main bioethics advisory group has given the green light to xenotransplantation - the transplantation into humans of organs taken from other animals - and endorsed the use of pigs, rather than primates such as chimpanzees and baboons, as the most acceptable source of such organs.

At the same time, the bioethics group points out in a report published in London last week that there is still considerable uncertainty about the potential hazards of xenotransplantation.

No clinical trials of the technique should be permitted, it therefore suggests, until the government has set up a new Advisory Committee on Transplantation, and this committee has given its approval to the proposed trials.

The report has been produced by a ten-member working party set up by the Nuffield Council on Bioethics. It comes at a time of growing interest in xenotransplantation, not only because of the growing gap between the number of patients awaiting transplants and the supply of human organs, but also because of hopes that some of the main scientific hurdles such as the 'hyperacute rejection' of pig organs by humans - may be close to resolution through genetic engineering.

Last year, for example, British scientists in the small company Imutran, based near Cambridge, announced that, having successfully bred pigs containing a human gene capable of switching off the production of the protein responsible for the hyperacute reaction, it confidently expected to begin clinical trials involving the transplantation of hearts from such pigs into humans before the end of 1996 (see Nature 377, 185; 1995).

The working group, which was chaired by
Albert Weale, professor of government at the University of Essex, concludes that the development of xenotransplantation "should continue", provided it is subject to "rigorous regulation" to ensure both the and adequate care of the animals involved.

Given both ethical concerns about using primates such as chimpanzees which are widely seen as closer biologically to humans than other animals, and the potential threat of extinction that could result from the wide-scale use of primates for transplant organs, the working group suggests that "non-primate species should be regarded as the source animals of choice". Indeed, it says that the breeding of pigs to supply organs for transplantation "would be ethically justified".

But the working group also concludes that the risks associated with the possible transmission of infectious diseases, including, for example, the spread of currently unknown animal viruses in humans that might be difficult to control, "have not been adequately dealt with". In the light of such uncertainty, it recommends a cautious approach, in particular stating that at present "it would not be ethical to begin clinical trials of xenotransplantation involving human beings".

The group says that standards and mechanisms for - monitoring xenograft recipients and for action to be taken in case of disease transmission "should be in place before human trials begin". It suggests that responsible both for developing these procedures and ensuring that they are properly applied. But it also admits that the setting up of such a committee is likely to encounter some reluctance from the UK Department of Health. protection of potential human recipients the proposed advisory committee should be

party committee was sufficiently frustrated by this response to call a further series of hearings designed explicitly to give various witnesses an opportunity to challenge the government's response.

Two weeks ago, for example, Sir David Weatherall, director of the University of Oxford's Institute of Molecular Medicine, and one of Britain's leading geneticists, told the committee that "in a very fast moving and complex field like genetics, some body is needed that is constantly monitoring things - if only because of their unpredictability - and is also able to reassure the public".

Last week, Dorrell told the committee that, having listened to the reactions to the government's response from both scientists and legislators, he had now accepted that the current monitoring arrangements might be insufficient to persuade the public that a broad perspective was being maintained on the commercial and ethical consequences of modern genetics.

As a result, he said, he had asked officials in his department to set up a review of aspects of the committee's proposal dealing with a body that would coordinate thinking across government of the direction and implications of developments in genetics.

Dorrell said that, given the specialist knowledge involved in many aspects of the

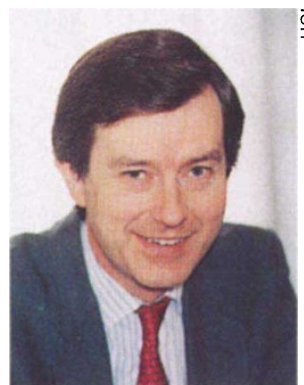

Dorrell: new body could "lead public opinion". applications of genetics, he was reluctant to abolish the existing advisory committees - or to turn them into subcommittees of a centralized body. Nor did he accept the committee's suggestion that a new body should be given a regulatory role, suggesting that "both government and Parliament would want to decide themselves how to react to the advice on offer".

This itself has frustrated some committee members, who have been pushing for a commission with the power to lay down strict guidelines to prevent abuses of genetic information in activities such as health screening, insurance and employment.

But Dorrell, in contrast to the government's earlier statement, acknowledged his concern that "at present, there are a range of [advisory] activities going on across the board without any coherence". A key role of an "over-arching" advisory committee would be "to catalyse thought on the implications of [modern genetics] in the form of advice to the government" and, in doing so, to "lead public opinion" on the issues involved, he said.
David Dickson 